\title{
Integrated Water Management With Reuse: A Programing Approach
}

\author{
David E. Pingry \\ University of Arizona, Tucson, Arizona 85721 \\ Timothy L. ShafTeL \\ University of Arizona, Tucson, A rizona 85721 \\ Queens University, Kingston, Ontario, Canada
}

Interest has increased recently in water recycling and reuse. The possible economic feasibility of reuse and recycling dramatically increases the complexity of designing an optimal water delivery system. In this peper presonta-monimoarmudotwhich takes into account both flow requirements and water quality. Because of the model's transshipment formulation the solution technique seems to be effective in aiding the design decisions.

\section{INTRODUCTION}

Interest has increased recently in water recycling and reuse. This interest has been stimulated by the recognition that in a growing number of regions large quantities of high quality water may no longer be available at low cost. The possible economic feasibility of reuse and recycling dramatically increases the complexity of designing an optimal water delivery system. The water system designer has available a number of natural sources of water, treatment processes, users and disposal sites. Given the appropriate technical, economic and legal constraints, he must select the least-cost delivery strategy.

Previous water system design models have been applications of the transportation or transshipment formulation of linear programing. Excellent examples of these models can be found in Bishop and Hendricks [1971], Bishop et al. [1978], Clausen [1970], Flinn and Day [1972], and Joeres et al. [1974]. Models of this type do not incorporate economies of scale associated with transportation and treatment costs. Also, in many models water quality is not explicitly considered within the framework of choosing among several recycling combinations.

The model in this paper allows for economies of scale in treatment and transportation. The quality of the flows is explicitly considered. The possibility of recycling water among many possible treatment processes, users and disposal sites is specifically included.

In the next section we present a physical description of the model. Section 3 offers a reformulation of the model into a nonlinear transportation problem and discusses the model solution. Section 4 discusses three example problems, while the last section provides some concluding remarks.

\section{Model}

A water management area can have water sources, water treatment plants, water users and water disposal sites. Water can flow from sources, treatment plants and users to treatment plants, users and disposal sites. Each of these flows has an associated 'quality.' This quality can be represented by a vector of numbers which are measured concentrations (weight/ volume) of various materials. Each water source can provide a bounded quantity of water of a given quality. Each treatment plant, user and disposal site has minimum acceptable quality standards for influent flow. Treatment plants affect the water

Copyright $\odot 1979$ by the American Geophysical Union. quality by removing some percentage of the material in the water. The actual percentage of a material a particular treatment plant removes is variable and bounded. Treatment plants cannot alter flow. Users alter the quality and the quantity of flow. Each user requires a specific level of influent flow which has a specified minimum quality. Each user has a specific effluent flow which may be less than or equal to the influent flow. In addition each user can add some specific amount of material (by weight) to the effluent flow. The disposal site can accept a bounded quantity of flow as long as it meets influent standards.

Given the appropriate information, the objective of the modeling effort described here is to determine a system design for providing each user with the desired quantity and quality of water. This design should minimize total cost while meeting all environmental and legal restrictions. The total cost of delivery and disposal is the sum of the piping cost, the treatment costs, the source costs and the disposal costs.

For convenience, the word node is used to designate a source, treatment plant, user or disposal site. It is also useful to separate notationally the nodes which supply flow from the nodes which demand flow. The fact that a node is a flow supplier does not necessarily imply that it originates flow. It may only act as a conduit, receiving flow from some other unit and passing it on. Likewise, the fact that a node is a flow demander does not require that all flow stop at that node. Let

$$
\begin{array}{ll}
g_{s} & \text { total number of available sources of water; } \\
g_{t} & \text { total number of treatment plants; } \\
g_{u} & \text { total number of users; } \\
g_{d} & \text { total number of disposal areas; } \\
g_{q} & \text { total number of different types of pollutants. }
\end{array}
$$

The following sets and subsets can now be defined:

Flow supply nodes

$$
I=\{1 \text { to } m\} \quad m=g_{s}+g_{t}+g_{u}
$$

Flow demand nodes

$$
J=\left\{g_{a}+1 \text { to } n\right\} \quad n=m+g_{d}
$$

Pollutant types

$$
K=\left\{1 \text { to } g_{q}\right\}
$$


Sources

$$
I_{s}=\left\{1 \text { to } g_{s}\right\}
$$

Treatment plants

$$
I_{t}=J_{t}=\left\{g_{s}+1 \text { to } g_{s}+g_{t}\right\rfloor
$$

Users

$$
I_{u}=J_{u}=\left\{g_{s}+g_{t}+1 \text { to } m\right\}
$$

Disposal areas

$$
J_{d}=\{m+1 \text { to } n\}
$$

It may be noted that some of these sets are redundant. They are defined in this way to enhance the clarity of the model. $I_{t}$ or $I_{u}$ will be used whenever flow is coming from a treatment plant or user. $J_{t}$ or $J_{u}$ will be used whenever flow is going to a treatment plant or user.

The model notation is as follows.

$q_{i j}$ decision variable denoting flow from node $i$ to node $j$ for $i \in I$ and $j \in J$ (volume/time);

$x_{i}{ }^{k} \quad$ decision variable denoting concentration of material $k$ flowing from node $i$ for $i \in I_{t}$ and $I_{u}$ and $k \in K$ (weight/volume);

$\bar{x}_{t}{ }^{k} \quad$ concentration of material $\boldsymbol{k}$ flowing from source $\boldsymbol{i}$ for $i \in I_{s}$ and $k \in K$ (weight/volume);

$y_{j}{ }^{k}$ maximum acceptable concentration of material $k$ at node $j$ for $j \in J$ and $k \in K$ (weight/volume);

$v_{j}^{k}$ maximum acceptable concentration of material $k$ at node $j$ from any single node for $j \in J$ and $k \in K$ (weight/volume);

$r_{i}$ maximum flow available at source $i$ for $i \in I_{s}$ (volume/time) or effluent flow from user $i$ for $i \in I_{u}$ (volume/time);

$p_{\jmath}=r_{t}$ maximum flow which can be processed by treatment plant $i$ or $j$ for $i \in I_{t}, j \in J_{t}, i=j$ (volume/time);

$p$, influent flow required by user $j$ for $j \in J_{u}$ (volume/ time) or maximum acceptable influent flow at disposal site $j$ for $j \in J_{d}$ (volume/time);

$z_{j}{ }^{k} \quad$ weight of material $k$ added by user $j$ for $j \in J_{u}$ and $k$ $\in K$ (weight/time).

Using the above notation the model constraints can be stated as

$$
\begin{aligned}
& \sum_{j \in J} q_{i j} \leq r_{i} \quad i \in I_{s} \\
& \sum_{i \in I} q_{i j}-\sum_{h \in J} q_{j h}=0 \quad j \in J_{t} \\
& \sum_{i \in t} q_{i j} \leq p_{j} \quad j \in J_{t} \\
& \sum_{i \in I} q_{i j}=p_{j} \quad j \in J_{u} \\
& \sum_{j \in J} q_{i j}=r_{i} \quad i \in I_{u} \\
& \sum_{i \in I} q_{i j} \leq p_{j} \quad j \in J_{d} \\
& \sum_{i \in I_{a}} \bar{x}_{i}{ }^{k} q_{i j}+\sum_{i \in T_{i}, I_{u}} x_{i}{ }^{k} q_{i j}-x_{j}^{k} \sum_{h \in J} q_{j n} \geq 0 \\
& j \in J_{t}, k \in K \\
& \sum_{i \in I_{s}} \bar{x}_{i}^{k} q_{i j}+\sum_{i \in I_{i}, I_{u}} x_{i}{ }^{k} q_{i j}-x_{j}^{k} \sum_{h \in J} q_{j h}+z_{j}^{k}=0 \\
& j \in J_{u}, k \in k
\end{aligned}
$$

$$
\begin{aligned}
& \sum_{l \in I_{s}} \bar{x}_{l}^{k} q_{i j}+\sum_{i \in I_{i}, I_{u}} x_{i}^{k} q_{i j} \leq y_{j}^{k} \sum_{i \in I} q_{l j} \\
& j \in J, k \in K \\
& x_{j}{ }^{k} \leq v_{j}{ }^{k} \text { for } \quad q_{u j}>0 \quad i \in I, j \in J, k \in K \\
& q_{i j}, x_{i}^{k} \geq 0 \\
& i \in I, j \in J, k \in K
\end{aligned}
$$

Constraints (2)-(7) are flow constraints. Constraint (2) states that the total flow from any source cannot exceed the total available water at that source. Constraint (3) assures that the total flow entering a treatment plant and the total flow leaving that plant will be equal. Constraint (4) states that flow entering a treatment plant must be less than the maximum amount which that treatment plant can process. Constraint (5) is used to insure that flow coming to each user will be equal to that user's total demand for water flow. Constraint (6) forces the water leaving each user to be equal to the portion of the total flow which that user does not consume. Constraint (7) insures that a disposal area does not receive water in excess of its capacity.

Constraints (8)-(11) are water quality constraints which are expressed in units of weight per unit of time. Constraint (8) insures that the amount of each material which enters a treatment plant is greater than or equal to the amount of that same material which leaves the treatment plant. Constraint (9) states that the amount of each material which enters a user node must be equal to the amount of that material which leaves the node plus the amount of that material added by the user. Constraint (10) says that the amount of material going to any node must be less than the product of an a priori determined maximum concentration level and the flow entering that node. This allows materials concentration in the influent flow for treatment plants, users and disposal sites to be limited. Constraint (11) limits the materials concentration of the influent flow entering a node from any other single node. In other words, constraint (10) limits the average materials concentration entering a node, while constraint (11) limits the maximum concentration from an individual node. Constraint (12) constrains the decision variables to be nonnegative.

Some additional relationships which will be useful in expressing the cost function for this model are presented below. Let

$$
f_{\jmath}=\sum_{\substack{l \in I \\ l \neq j}} q_{\mu}
$$

be the total flow from treatment plant $j$ for $j \in J_{t}$;

$$
e_{j}^{k}=\sum_{\substack{i \in I \\ i \neq j}} x_{i}^{k} q_{i j}
$$

be the total weight of pollutant $k$ entering treatment plant $j$ for $j \in J_{t}, k \in K$; and $w_{j}^{k}=e_{j}^{k}-x_{j} f_{j}$ be the amount of pollutant $k$ removed by treatment plant $j$ for $k \in K, j \in J_{t}$.

Using these expressions and cost parameters $a_{i j}, \alpha_{i j}, b_{j}{ }^{k}, \beta_{j}{ }^{k}$, $\gamma_{j}^{k}$ and $c_{i}$ the cost function (1) can be expressed as

$$
\begin{aligned}
& \sum_{i \in I} \sum_{\substack{j \in J \\
\text { pl plag costs }}} a_{i j} q_{i j} j^{\alpha l j}+\sum_{k \in K} \sum_{\substack{j \in J_{j} \\
\text { treatment costs }}} b_{j}^{k} f_{j} f_{j}^{k}\left(w_{j}^{k} / e_{j}^{k}\right)^{\gamma / j} \\
& +\sum_{i \in I_{s}} c_{i}\left(\sum_{j \in J} q_{i j}\right)+\sum_{k \in K} \sum_{\substack{j \in J_{d} \\
\text { disposal costs }}} c_{j}\left(\sum_{\substack{i \in I \\
x_{i}}} x_{i}^{k} q_{i j}\right)
\end{aligned}
$$

The functional forms of the cost functions are similar to those in Linaweaver and Clark [1964], Marsden et al. [1973], Shah and Reid [1970], and elsewhere. It is important to note that the 
solution technique developed in this paper is not dependent on specific functional form of the cost functions. In this particular formulation the source cost is linear in the volume of source flow. The disposal cost is nonlinear. However, it is linear in the weight of the material being disposed. This reflects the usual form of proposals for effluent charges. The piping cost is nonlinear in the flow rate. One would expect that $\alpha_{l j}$ would range from zero to one to reflect the economies of scale in piping. By the same reasoning one would expect $\beta_{j}{ }^{k}$ to range from zero to one to reflect economies of scale in treatment plants. However, $\gamma_{j}{ }^{k}$ would be expected to be greater than one to reflect diseconomies of high levels of removal.

\section{Model Reformulation and Solution}

The model presented in the last section contains two different sets of constraints. The first set, (2)-(7), are flow constraints, while the remaining constraints are related to quality. The first set of constraints can be reformulated as a transshipment form of the transportation problem where sources act as supply points (production plants) and disposal areas are demand points (markets). Treatment plants act as transshipment points (warehouses) which have a cost associated with throughput. Users are both transshipment points and demand points. Because the transshipment problem has inequality constraints, care must be taken in the determination of the right-hand sides of the reformulated problem. In order to accommodate the inequality constraints a 'dummy' source and a 'dummy' disposal are added to the model. For notational convenience, assume that $g_{s}$ and $g_{d}$ and the subsequent sets of indices have already taken these additions into account. The dummy source is $i=1$, while the dummy disposal area is $j=n$.

Costs associated with the two additional nodes are not the same as those shown in (1) for real sources and disposal sites. Since water cannot flow from the dummy source to treatment plants or users, the cost of this flow is assumed to be infinite. The same is true for flow from treatment plants and users to the dummy disposal site. On the other hand, flow from the dummy source to any disposal site and flow from any source to the dummy disposal site are free. It should also be noted that flow from a treatment plant to itself is an expedient of the transshipment formulation and provides a needed slack variable. In reality such a flow would not exist, and in the transshipment formulation this flow is free.

The transshipment formulation of the model is as follows:

$$
\begin{array}{ll}
\sum_{j \in J} q_{i j}=r_{i} & i \in I \\
\sum_{i \in I} q_{i j}=p_{j} & j \in J
\end{array}
$$$$
q_{\iota \jmath} \geq 0 \quad i \in I \quad j \in J
$$

where

and

$$
r_{1}=\sum_{j \in J_{u}, J_{d}-|n|} p_{j}-\sum_{t \in I_{u}} r_{l}
$$

$$
p_{n}=\sum_{\left.i \in I_{s}-\mid 1\right\}} r_{i}
$$

It is easy to show that constraints $\left(2^{\prime}\right)-\left(4^{\prime}\right)$ will satisfy all the conditions (2)-(7) for the original model with the costs as given above. The costless flow from any source to the dummy disposal site and that from the dummy source to any disposal site are slack variables which convert constraints (2) and (7) into equalities. Constraint (4) can also be expressed as an equality constraint; the slack variable in this case is the flow from a treatment plant to itself. With this in mind, constraint (3) and the fact that $I_{t}=J_{t}$ imply that $\sum_{j \in J_{t}} q_{t j}=p_{j}=r_{t}$ for $i$ $\in I_{t}, i=j$. Using this result in conjunction with equalities (2) and (3) yields (2'). Likewise, constraints (4), (6) and (7) imply $\left(3^{\prime}\right)$.

The reformulation of the flow restrictions of the model to a transshipment form can be used to advantage in developing a fast solution technique. If in addition the unknown concentrations $x_{i}{ }^{k}$ are set to some a priori values, the problem will become a transshipment problem with additional linear constraints and nonlinear objective function. The existence of fast solution techniques for transportation problems with linear objective functions [e.g., Srinivasan and Thompson, 1973] makes use of the transshipment structure of this problem an extremely reasonable approach. In particular, the work done on parametric transportation problems [Srinivasan and Thompson, 1972] provides added inducement for sequential choice of concentrations followed by the solution of a modified transportation problem. In terms of the nonlinear objective function, the convex simplex method [Zangwill, 1969] with upper bounded variables [Rutenberg, 1970] provides a structure which is developed along the lines of the traditional simplex method. The combination of a search mechanism over the concentrations with a fast solution technique for parametric transportation problems, modified for a nonlinear objective function, should lead to an efficient solution procedure for an extremely complex model. This approach was used to solve the example problems of section 4 with a great deal of success. For a presentation of a code of the convex simplex method applied to problems of the type discussed here see Rao and Shaftel [1977].

The salient features of the solution technique are outlined in Figure 1. The first step of the algorithm is to choose a value for the concentrations. Not all values of concentrations will lead to feasible solutions. Indeed constraints (8)-(10) can be used to develop both upper and lower bounds on the possible values of $x_{i}{ }^{k}$. Once the choice of $x_{i}{ }^{k}$ has been made, constraint (11) can be incorporated explicitly into constraints $\left(2^{\prime}\right)-\left(4^{\prime}\right)$ by forcing an infinite cost on any arc $i, j$ such that $x_{l}{ }^{k}>y_{j}{ }^{k}$. At least one solution to this problem exists. Assume all water is routed through a treatment plant. Further assume that each treatment plant removes all pollutants. Water is then routed to users. Clearly this represents a solution, albeit a poor one in most instances. Further qualifications such as limited treatment capacity or the barring of the use of recycled water could lead to situations where no feasible solution existed.

\section{Sample Problems}

To illustrate the model described in section 2, three sample problems based on data constructed for a hypothetical town named Aquatown are solved. Aquatown has three sources $\left(g_{s}\right.$ $=3)$, two treatment plant sites $\left(g_{t}=2\right)$, two users $\left(g_{u}=2\right)$ and three disposal areas $\left(g_{a}=3\right)$. Consistent with the transshipment form of the model, the first source and the last disposal site are dummy nodes. The other nodes are numbered consecutively from 2 to 9 . A schematic map of Aquatown with possible flows can be seen in Figure 2.

Aquatown's two possible sources of water are a well field west of town and a lake to the east. The flow from these sources can be routed to one of two potential treatment plant sites or to one of two users. One treatment plant site is located 


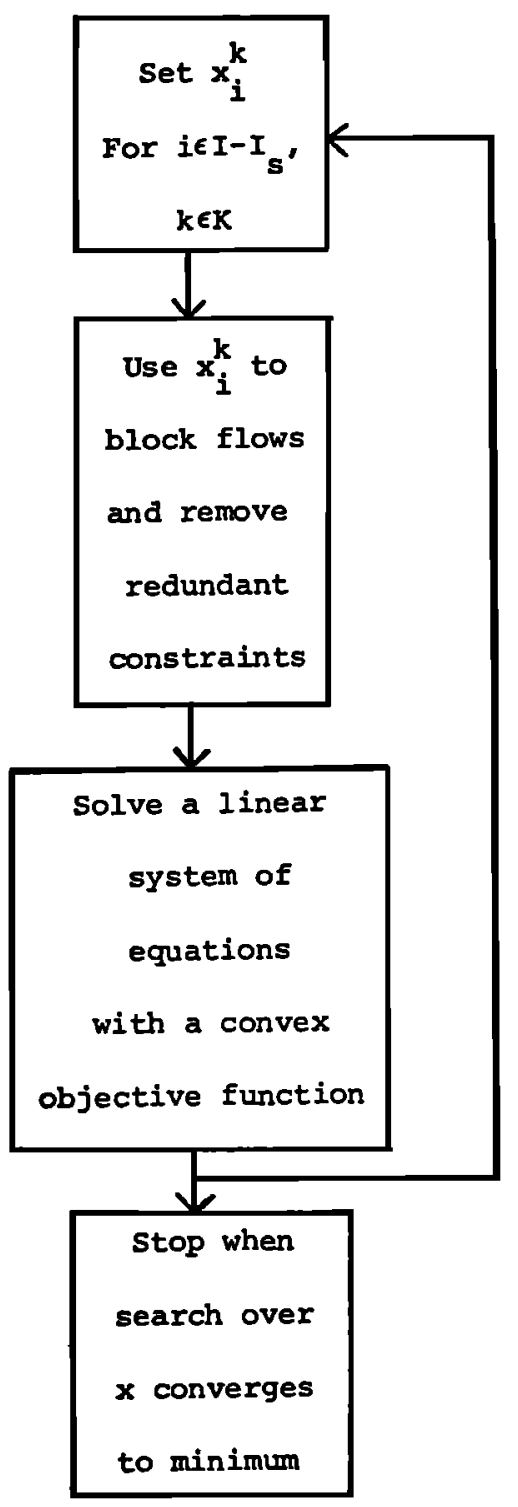

Fig. 1. Flow diagram of solution technique.

southwest of town near the river. Domestic water demand and industrial water are the two major users in Aquatown. The river at the south end of the lake and a water recharge area south of town are the possible disposal sites.

For the purpose of the following examples it is assumed that none of the installations has been constructed. This assumption is not required to solve the model. Existing structures can be considered by the proper alteration of cost functions and introduction of bounds on the appropriate decision variables.

The exposition of the sample problems can be simplified by introducing the transshipment tableau for the flow constraints. The tableau for sample problem 1 is illustrated in Figure 3. The units of the variables in the sample problems are identified with the following code: FU, flow units per unit time; $\mathrm{CU}$, weight units per flow unit; and WU, weight unit per unit time.

\section{Sample Problem 1}

For sample problem 1 sources 2 and 3 have available 100 FU $\left(r_{2}\right)$ and $50 \mathrm{FU}\left(r_{3}\right)$, respectively. The concentrations of these flows are $5 \mathrm{CU}\left(\bar{x}_{2}\right)$ for source 2 and $8 \mathrm{CU}\left(\bar{x}_{3}\right)$ for source 3. Treatment plants 4 and 5 can treat up to $200 \mathrm{FU}\left(r_{4}, r_{5}, p_{4}\right.$

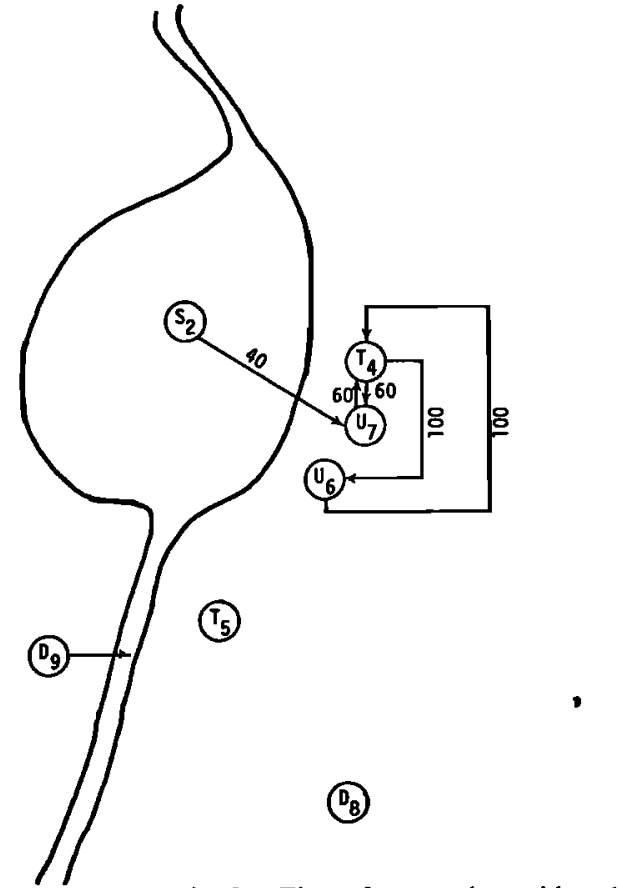

Fig. 2. Flows for sample problem 1.

and $p_{5}$ ). This flow must meet the required influent standard of $30.0 \mathrm{CU}\left(y_{4}\right.$ and $\left.y_{5}\right)$. In this case the upper bound on the size of the treatment plant is equal to the total flow demanded by the users.

User 6 requires $100 \mathrm{FU}\left(p_{6}\right)$ and consumes $40 \mathrm{FU}$, leaving an effluent flow of $60 \mathrm{FU}\left(r_{0}\right)$. The material concentration of the influent must be below $3.0 \mathrm{CU}\left(y_{0}\right)$. The effluent flow has an additional $500 \mathrm{WU}\left(z_{0}\right)$ of material 1 added by user 6 .

User 7 requires $100 \mathrm{FU}\left(p_{7}\right)$ and consumes none of the flow. Therefore, the effluent flow from user 7 is also $100 \mathrm{FU}\left(r_{7}\right)$. The concentration of influent must be below $5.0 \mathrm{CU}\left(y_{7}\right)$. The effluent has an additional $76 \mathrm{WU}\left(z_{7}\right)$ of material 1 added by user 7.

Disposal sites 8 and 9 both have limitations of $50 \mathrm{FU}\left(p_{8}\right.$ and $\left.p_{0}\right)$. The influent quality restrictions for sites 8 and 9 are, respectively, 7.0 CU and $6.0 \mathrm{CU}\left(y_{\mathrm{B}}\right.$ and $\left.y_{\theta}\right)$.

The cost function parameters for sample problem 1 are given in Tables 1, 2, and 3. The parameters are hypothetical,

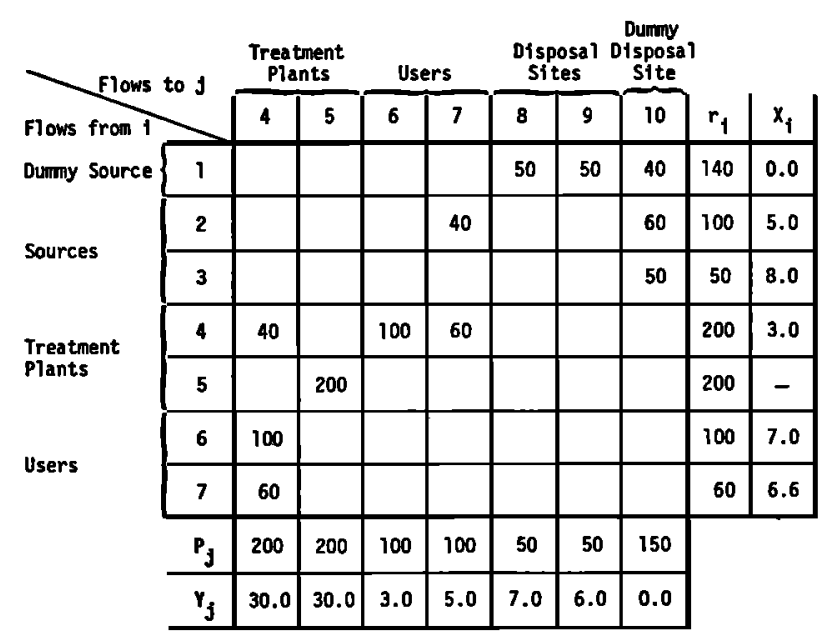

Fig. 3. Tableau for sample problem 1. For explanation of notation, see section 3 of text. 
TABLE 1. Piping Cost Parameters

\begin{tabular}{|c|c|c|c|c|c|c|}
\hline \multirow{2}{*}{$\begin{array}{l}\text { Value } \\
\text { of } i\end{array}$} & \multicolumn{6}{|c|}{ Value of $j$} \\
\hline & 4 & 5 & 6 & 7 & 8 & 9 \\
\hline 2 & 5 & 12 & 5 & 5 & 15 & 10 \\
\hline 3 & 20 & 15 & 20 & 25 & 20 & 25 \\
\hline 4 & 0 & 10 & 5 & 4 & 10 & 8 \\
\hline 5 & 12 & 0 & 15 & 16 & 5 & 2 \\
\hline 6 & 7 & 5 & 0 & 5 & 6 & 3 \\
\hline 7 & 8 & 7 & 2 & 0 & 8 & 6 \\
\hline
\end{tabular}

Here $\alpha_{i j}=0.5$ for all $i, I$ and $j \in J$.

but they reflect the accepted ranges on economies of scale.

The least cost solution to sample 1 is illustrated in Figures 2 and 3. In the optimal solution $40 \mathrm{FU}$ are obtained at source 2 . This flow is piped to user 7 . The additional required flow for user 7 is obtained from flow recycled through treatment plant 4. Treatment plant 4 has a removal rate of $56 \%$ and a design flow of $160 \mathrm{FU}$. The flow required for user 6 is also obtained from treatment plant 4 . Treatment plant 5 is not constructed.

In this particular example problem the cost of once through use-that is, source costs plus piping cost plus disposal site cost-is greater than the cost of recycling. The only flow obtained from the sources is necessary to make up the consumptive use of user 7 .

\section{Sample Problem 2}

For sample problem 2 a number of alterations are made in the Aquatown data with the purpose of making recycling less attractive. The cost structure is changed by increasing the cost of treatment and reversing the costs of water at the source. The exact amount of these changes can be seen in Tables 2 and 3. The high quality water which was relatively less expensive at the source is now relatively more expensive. All disposal charges are also eliminated.

In addition to the cost structure changes, a number of flow and concentration restrictions are altered. The flow available at source 3 was increased from $50 \mathrm{FU}$ to $100 \mathrm{FU}\left(r_{3}\right)$. This increases the total flow available at the sources to $200 \mathrm{FU}$. The total flow demanded by the users can now be supplied from the sources, which was not the case in sample problem 1 . In addition, the flow capacities at the disposal sites are increased from $50 \mathrm{FU}$ to $100 \mathrm{FU}\left(p_{\mathrm{B}}\right.$ and $\left.p_{\mathrm{g}}\right)$. The total disposal capacity is now large enough to support once through water use. The concentration restrictions at the disposal sites are also remarked.

The optimal solution to sample problem 2 is illustrated in Figures 4 and 5 . In spite of the efforts to 'price' recycling out of the solution, the optimal solution is similar to the solution to sample problem 2 . The major difference is that the source of

TABLE 2. Treatment Cost Parameters

\begin{tabular}{cl}
\hline Parameter & \multicolumn{1}{c}{ Value } \\
\hline$b_{4}$ & $23(120)^{*} \dagger \dagger$ \\
$b_{5}$ & $19(100)^{*}, \dagger$ \\
$\beta_{4}$ & $0.5(0.9) \dagger$ \\
$\beta_{5}$ & $0.6(0.9) \dagger$ \\
& \\
$\gamma_{4}$ & 1.5 \\
$\gamma_{5}$ & 1.7 \\
\hline
\end{tabular}

* Data change for sample problem 2.

$\dagger$ Data change for sample problem 3.
TABLE 3. Source and Disposal Costs

\begin{tabular}{cl}
\hline Source & Cost \\
\hline$C_{2}$ & $2(10)^{*}, \dagger$ \\
$C_{3}$ & $10(2)^{*}, \dagger$ \\
$C_{8}$ & 3 \\
$C_{9}$ & 1 \\
\hline
\end{tabular}

*Data change for sample problem 2.

tData change for sample problem 3.

the replacement flow is source 3 which is now relatively cheaper. Treatment plant 5 is selected over treatment plant 4 because it is relatively cheaper and closer to source 3 . The design capacity of treatment plant is $200 \mathrm{FU}$, and the removal rate is $60 \%$.

The reason that recycling is still the least-cost alternative is a result of the economies of scale in treatment. Since the sources have qualities of $5 \mathrm{CU}\left(x_{2}\right)$ and $8 \mathrm{CU}\left(x_{3}\right)$, respectively, the water must be treated before it is delivered to the users, which require $3 \mathrm{CU}\left(y_{8}\right)$ and $5 \mathrm{CU}\left(y_{7}\right)$, respectively. Therefore the cost of recycling is predominantly the incremental cost of making the treatment plant larger. Since there are large economies of scale in treatment plants, the incremental cost of a larger treatment plant is less than the cost of obtaining the flow from new sources.

\section{Sample Problem 3}

In sample problem 3, as in sample problem 2, an effort is made to price recycling out of the solution. Again the cost of treatment plants is increased. This is accomplished by increasing the flow scale parameters $\beta$ from 0.5 and 0.6 to 0.9 and 0.9 , respectively. This increases the incremental costs of treating for recycling.

The optimal solution for sample problem 3 , as illustrated in Figures 6 and 7, is more typical. The sources supply the total user demand. Source 2 routes 100 FU directly to user 7 which disposes of $60 \mathrm{FU}$ at disposal site 9 . User 6 obtains its $100 \mathrm{FU}$ from treatment plant 5 which in turn receives $100 \mathrm{FU}$ from

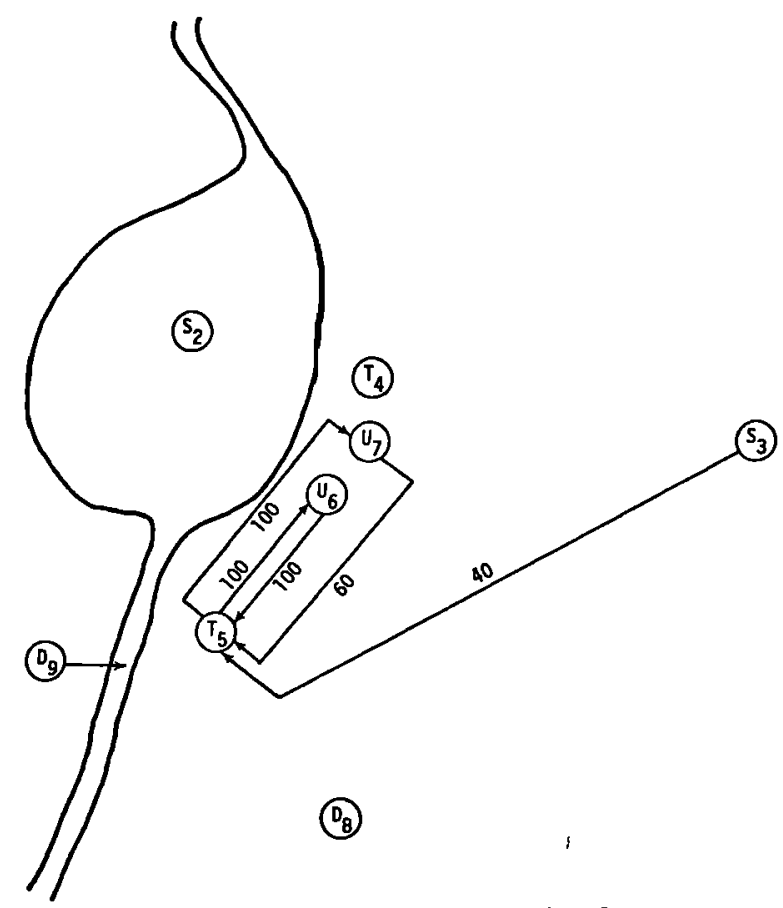

Fig. 4. Flows for sample problem 2. 


\begin{tabular}{|c|c|c|c|c|c|c|c|c|c|c|}
\hline \multirow{2}{*}{\multicolumn{2}{|c|}{ F) }} & \multicolumn{2}{|c|}{$\begin{array}{c}\text { Treatment } \\
\text { Plants }\end{array}$} & \multicolumn{2}{|c|}{ Users } & \multicolumn{4}{|c|}{$\begin{array}{c}\text { Disposay } \\
\text { Disposal Disposal } \\
\text { Sites Site }\end{array}$} & \multirow[b]{2}{*}{$x_{1}$} \\
\hline & & 4 & 5 & 6 & 7 & 8 & 9 & 10 & $r_{1}$ & \\
\hline \multirow[t]{2}{*}{ Dumny Source } & 1 & & & & & 100 & 100 & 40 & 240 & o \\
\hline & 2 & & & & & & & 100 & 100 & 5 \\
\hline Sources & 3 & & 40 & & & & & 60 & 100 & 8 \\
\hline \multirow{2}{*}{$\begin{array}{l}\text { Treatment } \\
\text { Plants }\end{array}$} & 4 & 200 & & & & & & & 200 & - \\
\hline & 5 & & & 100 & 100 & & & & 200 & 3 \\
\hline \multirow{4}{*}{ Users } & 6 & & 100 & & & & & & 100 & 8.0 \\
\hline & 7 & & 60 & & & & & & 60 & 6.27 \\
\hline & $P_{j}$ & 200 & 200 & 100 & 100 & 100 & 100 & 200 & & \\
\hline & $r_{j}$ & 30.0 & 30.0 & 3.0 & 5.0 & 15.0 & 15.0 & 0.0 & & \\
\hline
\end{tabular}

Fig. 5. Tableau for sample problem 2. For explanation of notation, see section 3 of text.

source 3. User 6 disposes of $100 \mathrm{FU}$ at disposal site 8. Treatment plant 5 has a design capacity of $100 \mathrm{FU}$ and a removal rate of $63 \%$

\section{Summary and Conclusions}

The model described in sections 2 and 3 can be applied at a variety of levels of aggregation. In the applications of the models in Bishop and Hendricks [1971], Bishop et al. [1978], Clausen [1970], and Flinn and Day [1972] to Tucson and Salt Lake County there is very little disaggregation of users. For example, in Clausen [1970] and Flinn and Day [1972], all domestic users in Tucson are lumped together. In Bishop and Hendricks [1971] the Salt Lake County is divided into six regions. The choice of this level of aggregation probably reflects data limitations and a desire to speed computation. In addition, the applications are presented mainly as sample case studies. However, these examples serve to illustrate the problems of not explicitly considering economies of scale. The

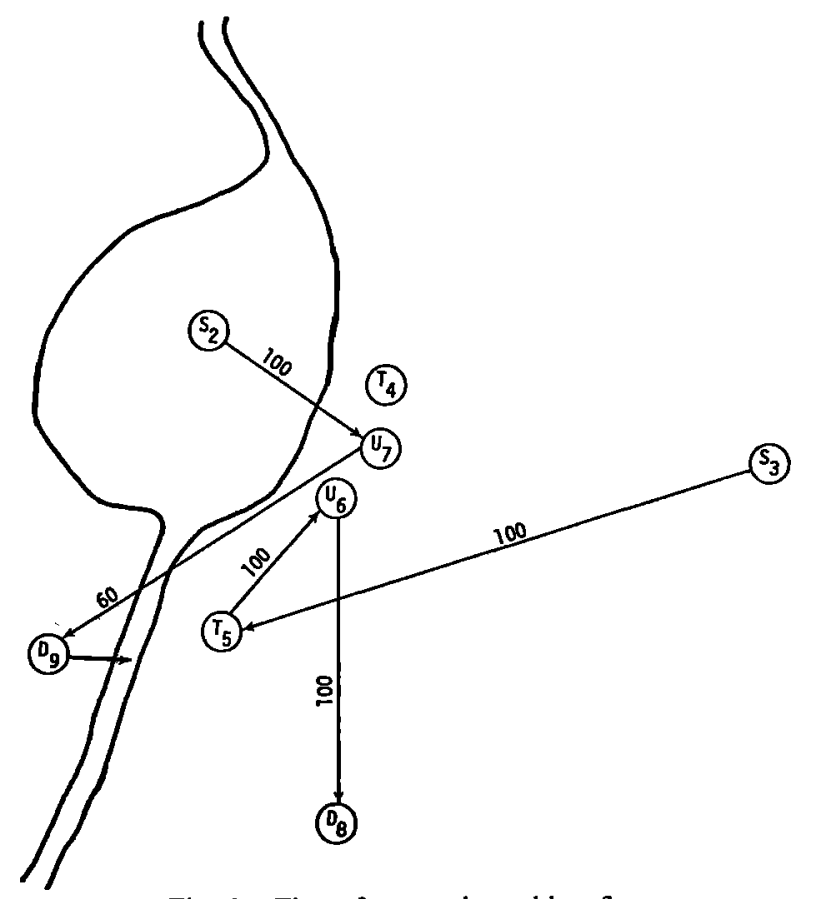

Fig. 6. Flows for sample problem 3.

\begin{tabular}{|c|c|c|c|c|c|c|c|c|c|c|}
\hline & \multicolumn{2}{|c|}{$\begin{array}{c}\text { Treatment } \\
\text { Plants }\end{array}$} & \multicolumn{2}{|c|}{ Users } & \multicolumn{3}{|c|}{$\begin{array}{c}\begin{array}{c}\text { Dummy } \\
\text { Disposal } \\
\text { sisposal } \\
\text { Sites Site }\end{array} \\
\end{array}$} & \multirow[b]{2}{*}{$r_{i}$} & \multirow[b]{2}{*}{$x_{f}$} \\
\hline & & 4 & 5 & 6 & 7 & 8 & 9 & 10 & & \\
\hline \multirow[t]{2}{*}{ Durmy Source } & 1 & & & & & & 40 & 200 & 240 & 0.0 \\
\hline & 2 & & & & 100 & & & & 100 & 5.0 \\
\hline Sources & 3 & & 100 & & & & & & 100 & 8.0 \\
\hline \multirow{2}{*}{$\begin{array}{l}\text { Treatment } \\
\text { Plants }\end{array}$} & 4 & 200 & & & & & & & 200 & - \\
\hline & 5 & & 100 & 100 & & & & & 200 & 3.0 \\
\hline \multirow{4}{*}{ Users } & 6 & & & & & 100 & & & 100 & 8.0 \\
\hline & 7 & & & & & & 60 & & 60 & 9.6 \\
\hline & $P_{j}$ & 200 & 200 & 100 & 100 & 100 & 100 & 200 & & \\
\hline & $Y_{1}$ & 30.0 & 30.0 & 3.0 & 5.0 & 15.0 & 15.0 & 0.0 & & \\
\hline
\end{tabular}

Fig. 7. Tableau for sample problem 3. For explanation of notation, see section 3 of text.

practice of assuming a treatment cost which is linear in flow presupposes the scale economies which are to be obtained and, in effect, defines the size of the decision unit. If the cost coefficient is assumed for a large plant, then only large plants should be allowed in the solution. This may eliminate some cost effective reuse and recycling strategies.

Consider, for example, the alternative of using treated effluent for the irrigation of parks, school grounds, golf courses and other public areas. If these facilities are scattered throughout a large city, it may make economic sense to build small treatment plants near these facilities. The savings in transportation cost to a central plant may exceed the loss of scale economies.

There are a number of other interesting trade-offs which are embodied in the proposed model. For example, sewer systems have generally been designed to take advantage of gravity as much as possible. This is fine as long as the goal is simply to remove the effluent from the city and return it to the natural cycle. However, if the effluent is to be reused at a point which is not downstream of the city, it may make sense to incur higher transportation cost in the collection system rather than incurring the transportation cost after treatment of the effluent.

Another interesting trade-off is illustrated in the sample problems. An increase in treatment costs increases the cost of disposal when there are environmental quality standards. One would surmise that this increase would induce more recycling. However, the increase in treatment costs also increases the cost of recycling. The actual outcome depends on how much additional treatment is required for recycling.

There are numerous applications of the model presented above. A water utilities manager or planner could use such a system to plan expansions of existing systems or entirely new systems. The cost implications of various policy proposals could be quickly evaluated. For example, the cost of changes in environmental standards or imposition of an effluent tax could be quickly determined. Regions would no longer be locked into '5-year' capital expansion plans. These plans could be generated continually as new data are obtained.

The gains in realism made by explicit consideration of economies of scale and the quality of the flows should greatly increase the applicability of the systems approach to water delivery planning. The cost of the increased sophistication, as always, is increased solution time and cost. The solution tech- 
nique outlined in section 3 should minimize the additional computational costs by taking advantage of the transshipment formulations of the flow submodel.

\section{REFERENCES}

Bishop, A. B., and D. W. Hendricks, Water reuse systems analysis, $J$. Sanit. Eng. Div. Amer. Soc. Civil Eng., 7(3), 542-553, 1971.

Bishop, A. B., B. C. Jensen, and R. Narayanan, Economic assessment of an activity analysis model for water supply planning, submitted to Water Resour. Res., 1978.

Clausen, G. S., Optimal operation of water supply systems, Tech. Rep. I, Hydrol. and Water Resour., Univ. of Ariz., Tucson, June 1970

Flinn, J. C., and J. C. Day, Towards the integrated management of water supplies in the Tucson region of Arizona, paper presented at meeting, West. Agr. Ass., Logan, Utah, 1972.

Joeres, E. F., J. Dressler, C.-C. Cho, and C. H. Falkner, Planning methodology for design of regional waste water treatment systems, Water Resour. Res., lO(4), 643, 1974.

Linaweaver, F. P., and C. S. Clark, Cost of water transmission, $J$. Amer. Water Works Ass., 56(12), 1549-1560, 1964.

Marsden, J. R., D. E. Pingry, and A. Whinston, Regression analysis applied to the wastewater treatment field, J. Water Pollut. Control Fed., 45(10), 2104-2109, 1973.
Rao, R. C., and T. Shaftel, An efficient algorithm for solving transportation problems with nonlinear objective functions, paper presented at Joint National Meeting, Oper. Res. Soc. of Amer. and Inst. of Manage. Sci., San Francisco, Calif., May 1977.

Rutenberg, D. P., Generalized networks, generalized upper bounding and decomposition of the convex simplex method, Manage. Sci., 16, 388-401, 1970.

Shah, K. L., and G. W. Reid, Techniques for estimating construction costs of waste treatment plants, J. Water Pollut. Control Fed., 42(5), 776-793, 1970.

Srinivasan, V., and G. L. Thompson, An operator theory of parametric programming for the transportation problem, I, II, Nav. Res. Logistics Quart., 205-225, 1972.

Srinivasan, V., and G. L. Thompson, Benefit-cost analysis of coding techniques for the primal transportation algorithm, J. Ass. Comput. Mach., 20, 194-213, 1973.

Zangwill, W., Nonlinear Programming: A Unified Approach, chaps. 8, 9, Prentice-Hall, Englewood Cliffs, N. J., 1969.

(Received December 30, 1975; revised May 1, 1978; accepted August 9, 1978.) 